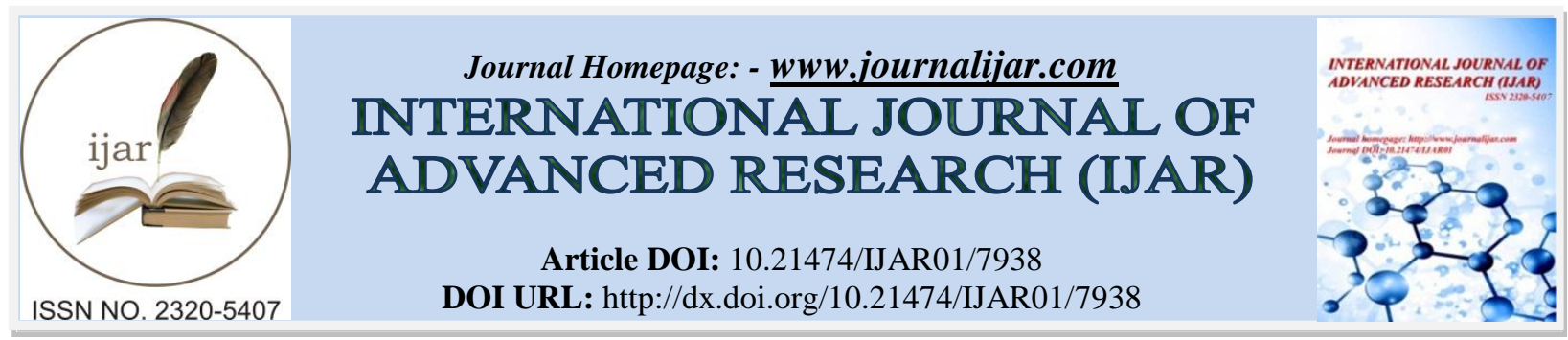

RESEARCH ARTICLE

\title{
EFFECTIVENESS OF STRUCTURED TEACHING PROGRAMME ON KNOWLEDGE REGARDING IRON DEFICIENCY ANAEMIA AMONG ADOLESCENT GIRLS OF JAWAHARLAL NEHRU INTER COLLEGE KALYANPUR, KANPUR.
}

\author{
Mrs. Jasmi Manu ${ }^{1}$, Mr. Mayur Samuel ${ }^{2}$, Miss. Jyotsna Sharma ${ }^{3}$ and Mr. Man $\operatorname{singh}^{4}$. \\ 1. Asso.Professor, Cum H.O.D of OBS/GYN Nursing. \\ 2. Rama College of Nursing, Rama University Mandhana Kanpur.
}

\section{Manuscript Info}

Manuscript History

Received: 15 August 2018

Final Accepted: 17 September 2018

Published: October 2018

Keywords:-

STP, Iron deficiency anemia,

Adolescent girls.

\begin{abstract}
A pre experimental study was conducted to evaluate the effectiveness of structured teaching programme on knowledge regarding iron deficiency anemia among adolescent girls of Jawaharlal Nehru Inter college Kanpur. The research design was one group pretest post test design. The sample of the study is adolescent girls in Jawaharlal Nehru Inter College Kalyanpur. The Sample size was 40, selected by purposive sampling technique. The mean of overall pre test knowledge score was 13.6 and the mean of overall post test knowledge score was 19.9. Improvement in the knowledge score of the samples from pre test to post was tested for statistical significance using paired t-test $(\mathrm{t}=2.269)$, shows significant difference between pre and post test score $(\mathrm{p} 0.05)$
\end{abstract}

Copy Right, IJAR, 2018,. All rights reserved.

\section{Introduction:-}

Adolescent would be the best investment for future....Sundarlal ${ }^{l}$

Adolescence has been defined by the World Health Organization as the period of life spanning the ages between 13 to 19 years. This is the formative period of life when the maximum amount of physical, psychological and behavioral changes take place. This is a vulnerable period in human life cycle for the development of nutritional anemia, which has been constantly neglected by public health programme ${ }^{2}$. Girls are more likely to be victims due to various reasons in a family with limited resources. ${ }^{3}$ Adolescent is a period of second decade of life. They constitute over one fifth of India's population ${ }^{1}$.

Total Nutrient requirements are increase during adolescence age is to support a period of dramatic growth and development. Eating right food at right time will prevent the nutritional deficiencies especially Iron deficiency disorders among adolescence ${ }^{4}$. WHO graded the hemoglobin level $10 \mathrm{~g} / \mathrm{dl}$ is considered as mild iron deficiency anemia, hemoglobin between $7 \mathrm{~g} / \mathrm{dl}$ to $10 \mathrm{~g} / \mathrm{dl}$ is considered as moderate iron deficiency anemia and hemoglobin less than $7 \mathrm{~g} / \mathrm{dl}$ is considered as severe iron deficiency anemia ${ }^{5}$. Iron deficiency anemia cause approximately half of all anaemia cause worldwide, and affect women more often than men . iron deficiency anemia affected 1.2 billion $^{6}$. People in 2013, anemia due to iron deficiency resulted in about 183,000 death down from 213,000 death in $1990^{7}$ .Nowadays the young adolescent faces many problems because of their life style modifications such as eating Jung foods, fast foods, snacking, skipping of the meals which is common in urban adolescent girls ${ }^{8}$. Some are malnourished due to lack of knowledge about dietary iron, poor socio economic status, low income family which is 
common in rural areas and also in menstrual period the adolescent girls used to lose $45 \mathrm{ml}$ of blood (i.e.) $22 \mathrm{mg}$ of iron $^{8}$.

High prevalence of iron deficiency anemia reflects their poor status of nutrition because of their rapid growth combined with poor eating habits and menstruation ${ }^{6}$. In world health report of World Health Organization (WHO) states that the world wide morality rate of iron deficiency anemia is $60,404,000$ in $2005^{9}$. In order to tackle this public health problem a multi-prolonged 12 x 12 initiative has been launched by Family and Community Health Department in India ${ }^{10}$. The initiative is targeted at all adolescents across the country with the aim for achieving hemoglobin level of $12 \mathrm{~g} / \mathrm{dl}$ by the age of 12 years by $2012 .{ }^{10}$ Based on these information the researcher feels that it is important to educate regarding prevention of the iron deficiency anemia among adolescent girls.

\section{Objectives of the study:-}

1. To assess the knowledge of adolescent girls regarding iron deficiency anemia.

2. To evaluate the effectiveness of structured teaching programme on iron deficiency anemia among adolescent girls.

3. To find out the association between the pre-test knowledge score and selected demographic variables.

\section{Hypothesis:-}

$\mathbf{H}_{1}$ :-There is a significant difference between mean pre-test knowledge score and mean post-test knowledge score regarding iron deficiency anemia.

$\mathbf{H}_{2}$ :-There is a significant association of pre-test knowledge score with selected demographic variables

\section{Materials and methods used:-}

Research design: Pre-experimental (one -group) pre- test and post- test design was used for the present study.

Research approach: Descriptive evaluatory approach was used for the present study

Setting of the study: The study was conducted in Jawaharlal Nehru inter college Kalyanpur

Population: Population for the present study was all adolescent girls studying $11^{\text {th }}$ standard

Sampling: Purposive sampling technique was used to select 40 adolescent girls of Jawaharlal Nehru Inter college kalyanpur who fulfilled the sampling criteria for the present study.

Sample size: 40 adolescent girls

\section{Variables:}

Dependant variable: Knowledge of adolescent girls is the dependent variables

Independent variable: In this present study Structured teaching programme on iron deficiency anaemia was the independent variable

Demographic variables:- age, residence, educational status, occupation of the parents, monthly family income ,types of family and Type of diet

\section{Sampling criteria:-}

Inclusive criteria:-

1. Adolescent girls 13-19 years

2. Participants who are willing to participate in this study.

3. Participants who are available during the period of data collection

4. Those who knows English or Hindi

5. Those who are studying in 12 th standard

\section{Exclusion criteria:-}

1. Who has attended any health programme regarding anemia screening programme

2. Those who were under treatment of anemia

\section{Development and description of tools used in the study:-}

The tool to assess the knowledge of adolescent girls on iron deficiency anemia was developed by the investigator after reviewing the literature .validity and reliability of the tool was checked

\section{Description Of The Tool}


The structured questionnaire consisted of 2 sections.

1. Demographic data:-Section A- consist of demographic data including age, residence, education of the parents, occupation of the parents, income of the family, type of family, type of diet, number of children and information.

2. Questionnaire:-There are structured closed ended questionnaire to assess the knowledge of adolescent girls regarding iron deficiency anemia .Total 26 items were selected for the questionnaire. A blue print was prepared.

\section{Scoring -}

1. Score 1 was given to every correct answer.

2. Score 0 was given to every wrong answer. Based on the percentage of scores, level of knowledge was graded as follows.

Table 1:-The total knowledge score were categorized into

\begin{tabular}{|l|l|l|l|}
\hline Sr.no. & level of knowledge & score range & scorein percentage \\
\hline $\mathbf{1}$ & Poor & $0-8$ & $\leq 30.76 \%$ \\
$\mathbf{2}$ & Average & $9-16$ & $34.61-61.53 \%$ \\
$\mathbf{3}$ & Good & $17-26$ & $65.38-100 \%$ \\
\hline
\end{tabular}

\section{Data Collection Procedure}

The data collection was scheduled in the month of April 2016 two weeks(18-04-2016 TO 30-04-2016). Before the data collection the investigator obtained prior permission from the principal of Jawaharlal Nehru Inter college kalyanpur to conduct the study in their Institution. Written consent taken from the samples.40 samples were selected by purposive sampling technique, who fulfill the inclusion criteria. The structured questionnaire was administered to collect the data from the adolescent girls. Structured teaching programme was administered to the students. The evaluation of STP was planned through post- test after 5 days of implementation of STP programme

\section{Plan for data analysis:}

The data obtained from 40 samples were analyzed by adopting the Descriptive statistics as frequency and percentage of samples, mean, standard deviation and inferential statistics. The analysis was to be done based on the objectives and hypothesis to be tested.

The investigator planned to analyze the data in the following manner-

Section I:-Percentage wise distribution according to their demographic variables

Section II:- Pre-test knowledge score regarding knowledge on iron deficiency anaemia

Section III:- Post test knowledge score regarding knowledge on iron deficiency anaemia

Section IV:-Effectiveness of structured teaching programme on iron deficiency anaemia.

Section v:-Association of Pre-Test knowledge score with selected demographic variables.

\section{Data analysis and major findings:-}

Section 1:-demographic data

1. Majority of girls belonged to $16-17$ years group (47.5\%).

2. Majority of them belonged to Hindu religion (90\%).

3. Most of them to joint family $(60 \%)$.

4. Most of them lived in pucca house $(62.5 \%)$.

5. Most of them reside in rural area $(60 \%)$.

6. Most of them had a family income between 4,000-10,000 (65\%).

Section II:- Level of Pre-Test Knowledge Score Among Adolescent Girls Regarding Iron Deficiency Anemia Among 40 adolescent girls , the majority of respondent(33) 82.5\% had average level of knowledge and $12.5 \%$ had good level of knowledge and $5 \%$ had poor level of knowledge.

\section{Section III:- Level Of Post Test Knowledge Score Among Adolescent Girls Regarding Iron Deficiency} Anemia

After structured teaching programme the post test knowledge score among 40 adolescent girls, $2.5 \%$ had average level of knowledge and $97.5 \%$ had good average level of knowledge. 


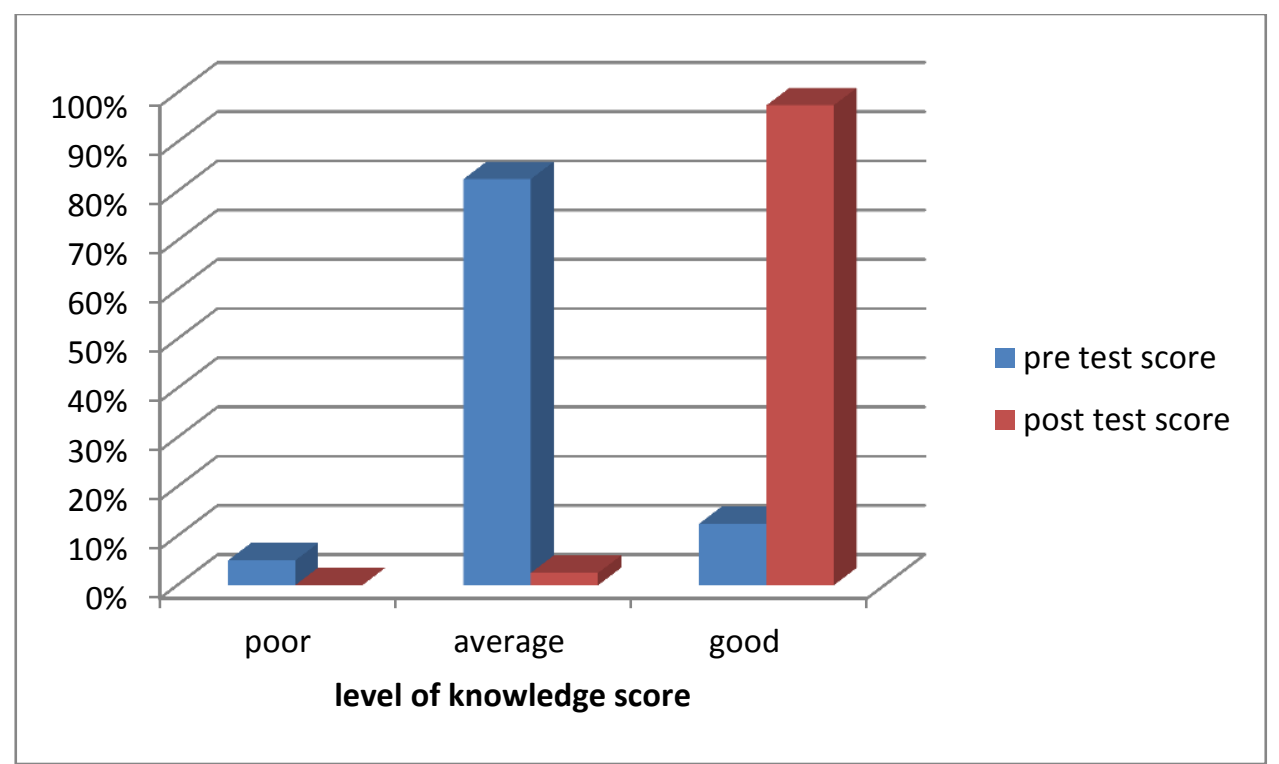

Figure 1:-bar diagram showing the level of pre and post test knowledge of adolescent girls regarding iron deficiency anemia

Section IV: - Effectiveness of structured teaching programme on iron deficiency anaemia ( Difference Between Pre-Test Knowledge Score And Post- Test Knowledge Score

Table2:-Overall mean, $\mathrm{SD}$, and paired -t value of pre-test and post test score

\begin{tabular}{|l|l|l|l|l|l|l|}
\hline & & $\mathbf{N}$ & Mean & Sd & T-value & P \\
\cline { 3 - 6 } Knowledge score & Pre-test & 40 & 13.6 & 7.8 & & \\
\cline { 2 - 5 } & Post-test & 40 & 19.9 & 8.0 & \multirow{2}{*}{2.269} & \multirow{2}{*}{0.05} \\
\hline
\end{tabular}

The mean score before and after administration of structured programme has shown a significant difference .The mean total knowledge score before intervention was 13.6 which has increased to 19.9 after intervention the paired $t$ test 2.269 was found to be significance at a very high level $(\mathrm{p}=0.05)$.

From the above inference it is made clear that the structured teaching programme has a positive impact on knowledge of iron deficiency anaemia $(\mathrm{p}<0.05)$ so $\mathrm{h}_{1}$ is accepted

Section V:-Association between the demographic variables and knowledge score of subjects on knowledge iron deficiency anaemia

There was no association between the pre-test knowledge score and selected demographic variables such as age in year, residence, education of the parents, income of the parents , type of family, type of diet , number of children, information except occupation of parents.There is an association of knowledge score with occupation of the parents at 0.05 level of significant. Hypothesis is retained only to occupation of parents.chi square value was used to check the association.

\section{Conclusion:-}

The study significantly proved that there is a remarkable improvement in the knowledge of adolescent girls regarding iron deficiency anaemia after structured teaching program. There was no significant association between age in year, residence, education of the parents income of the parents, type of family type of diet, number of children, information with regards to iron deficiency anaemia $(\mathrm{p}<0.05)$ where as there was an association found between occupation of the parents and knowledge adolescent girls regarding iron deficiency anaemia 


\section{Recommendations:-}

1. The similar study can be replicated on large sample.

2. A study can be conducted in a Jawaharlal Nehru inter college by using large sample of adolescent girls.

3. A comparative study can be done to see the effectiveness study in rural and urban area.

4. A study can be planned for management of iron deficiency anaemia

\section{Bibliography:-}

1. Ramakanth,S.S (2006) nutritional anemia and its control.India Journalof pediatrics, page no 69,607-616.

2. Janz,TG Johonson,RL Rubenstein.Anemia in the Emergency Department Evaluation and Treatment.Emergency Medicine Practice.2013 nov;15(11):1-15.

3. Calis Jc, Phiri KS,Faragher EB,et al. severe Anemia in Malawian children. N.Engl.J.med. (2008) 358(9): 888899

4. R.Morlow Dorthy. Text Book Of Paediatrics. $6^{\text {th }}$ edition.published by Elesevier publisher,published in New Delhi 2007. page no 1133-1136

5. Park K.Text Book Of Preventive and Social Medicine. $18^{\text {th }}$ Edition published By Bhanot. Published in Jabalpur 2007.pageno 449-450

6. Global Burden Of Disease Study 2013,Collaborators.global,regional,and national incidence, prevalence, and years lived with disability for 301 acute and chronic diseases and in countries,1990-2013:a systematic analysis for the Global Burden of disease study 2013. Lancet(London England) 2015 August; 386 (9995): 743-800

7. GBD 2013 Mortality and cause of death, Collaborators. Global, Regional , and National Age- Sex Specific All Cause and cause specific mortality for 240 cause of death,1990-2013:a Systematic analysis for the Global Burden Of Disease Study 2013.Lancet 2014 december;385 (9963): 117-71

8. Gupta Suraj. Text Book O Paediatrics. $11^{\text {th }}$ edition published by Jaypee brothers. published in New Delhi 2009. page no 212-214

9. Department of Family and Community Health, National family health servey-3(2005-2006),www.indiastat.com. 